\title{
ESTACIONALIDADE E ESTABILIDADE DE PRODUÇÃO DE FORRAGEM DE PROGÊNIES DE Brachiaria ruziziensis ${ }^{1}$
}

\author{
Seasonality and stability of forage production of Brachiaraia ruziziensis progenies ${ }^{1}$
}

\author{
Fausto Souza Sobrinho², Francisco José da Silva Lédo ${ }^{3}$, Maurício Marini Kopp ${ }^{4}$
}

\begin{abstract}
RESUMO
Conduziu-se este trabalho, com o objetivo de avaliar a produtividade de biomassa de forragem de progênies de Brachiaria ruziziensis e a estabilidade de produção ao longo de diferentes cortes, representativos de épocas favoráveis e desfavoráveis ao desenvolvimento das forrageiras. Foram avaliadas 118 progênies de $B$. ruziziensis, juntamente com as testemunhas $B$. decumbens cv. Basilisk, B. brizantha cv. Marandu, B. ruziziensis cv. Comum e Brachiaria sp., em delineamento de blocos casualisados, com duas repetições. Realizaram-se sete cortes de avaliação com intervalos médios de 60 e 90 dias nas épocas das águas (5 cortes) e das secas (2 cortes). Em cada um deles mensurou-se a altura das plantas (ALT) e as produtividades de biomassa de forragem verde (PBV) e seca (PBS). As médias dos diferentes cortes, nas épocas das águas ou das secas, foram utilizadas para a realização de análises de variância, em esquema fatorial (progênies $\mathrm{x}$ épocas), para a avaliação dos efeitos de estacionalidade de produção das progênies. Também foi realizada a avaliação da estabilidade das progênies. Apesar da grande concentração da PBV e PBS na época das águas, detectou-se a existência de variabilidade genética entre progênies de $B$. ruziziensis para ALT, PBV e PBS, tanto na época das águas como na seca. Alguns materiais avaliados apresentaram estabilidades de produção superiores às principais cultivares comerciais de Brachiaria, indicando ser possível a identificação e seleção de materiais de B. ruziziensis com médias mais elevadas e com produção mais estável ao longo do ano.
\end{abstract}

Termos para indexação: Brachiaria, produção de inverno, adaptabilidade, melhoramento de forrageiras.

\begin{abstract}
The objective of this study was to evaluate the forage biomass productivity of Brachiaria ruziziensis progenies and yield stability over different cuts, representing favorable and unfavorable periods of forage development. 118 progenies of $B$. ruziziensis and the controls B. decumbens cv. Basilisk, B. brizantha cv. Marandu, B. ruziziensis cv. Common and Brachiaria sp. were evaluated using a randomized block design with two replicates. There were seven cuts assessment with an average interval of 60 and 90 days in water (5 cuts) and dry ( 2 cuts) seasons. In each cut, plants height (ALT) and dry (PBS) and green (PBV) biomass forage yield were measured. The averages of the different cuts made in dry or water seasons were used to perform statistical analysis in a factorial (progeny $\mathrm{x}$ times) for the effects of progeny production seasonality. The stability analysis also was performed. Despite the large concentration of PBV and PBS in the rainy season, the existence of genetic variability between progenies of $B$. ruziziensis for ALT, PBV and PBS were observed in both rainy and dry seasons. Some evaluated materials showed production stabilities higher than commercial cultivars of Brachiaria indicating the possibility of identification and selection of $B$. ruziziensis material with higher average and stable production over the year.
\end{abstract}

Index terms: Brachiaria, winter production, adaptability, forage breeding.

(Recebido em 12 de março de 2010 e aprovado em 17 de janeiro de 2011)

\section{INTRODUÇÃO}

A produção de leite e carne de bovinos no Brasil está baseada na utilização de pastagens, por constituírem alimento de menor custo para o produtor. Para que os animais possam expressar todo o seu potencial produtivo, é necessária uma alimentação adequada. Exige-se, portanto, a disponibilização de forragem de qualidade durante todo o ano (SOUZA SOBRINHO et al., 2005). Entretanto, as forrageiras tropicais, de modo geral, apresentam grande concentração da produção de forragem durante a época das águas (OLIVEIRA et al., 2010; FERNANDES et al., 2010), que apresenta condições mais favoráveis ao seu desenvolvimento (MOREIRA et al., 1996), como temperatura e umidade (SOARES FILHO et al., 2002).

Embora o número de espécies forrageiras disponíveis no Brasil seja elevado, os gêneros Brachiaria e Panicum apresentam maior importância, expressa pela maior área cultivada e pelo grande valor agregado ao comércio de suas sementes (PEREIRA et al., 2001). Dentro do gênero Brachiaria, a $B$. ruziziensis é a única espécie

${ }^{1}$ Trabalho parcialmente financiado com recursos da FAPEMIG, CNPq e UNIPASTO

${ }^{2}$ Empresa Brasileira de Pesquisa Agropecuária/Embrapa - Gado de Leite - Rua Eugênio do Nascimento - 610 - Dom Bosco - 36038 -330 - Juiz de Fora, MG - fausto@cnpgl.embrapa.br

${ }^{3}$ Empresa Brasileira de Pesquisa Agropecuária/Embrapa - Gado de Leite - Juiz de Fora, MG

${ }^{4}$ Empresa Brasileira de Pesquisa Agropecuária/Embrapa - Pecuária Sul - Bagé, RS 
cultivada no Brasil que é diplóide e que apresenta reprodução sexual, permitindo a seleção e recombinação de materiais superiores (SOUZA SOBRINHO, 2005).

Dentro dos programas de melhoramento de forrageiras, uma característica que deve ser considerada é a estabilidade de produção dos materiais, buscando-se selecionar materiais com melhor adaptação às diferentes condições ambientais. No caso das forrageiras perenes, os diferentes cortes realizados durante as avaliações, que normalmente são superiores a um ano, podem ser utilizados como variação para a seleção de materiais com menor estacionalidade de produção (SOUZA SOBRINHO et al., 2005). Materiais com médias de produtividade mais elevadas nos diferentes cortes e com menor queda durante os períodos de estresse ambientais devem ser identificados e selecionados para prosseguimento do melhoramento genético.

Neste trabalho, objetivou-se foi avaliar a produtividade de forragem de progênies de $B$. ruziziensis e a estabilidade de produção ao longo de diferentes cortes, representativos de épocas favoráveis e desfavoráveis ao desenvolvimento das forrageiras.

\section{MATERIAL E MÉTODOS}

O experimento foi conduzido no Campo Experimental de Coronel Pacheco (MG), da Embrapa Gado de Leite. Foram avaliadas 118 progênies de meio-irmãos de Brachiaria ruziziensis, juntamente com as testemunhas $B$. decumbens Stapf. cv. Basilisk, B. brizantha (Hochst. ex A. Rich.) Stapf. cv. Marandu, B. ruziziensis Germain \& Evrard. cv. Comum e Brachiaria sp., em delineamento de blocos casualisados, com duas repetições e parcelas de $3 \mathrm{~m}$, com espaçamentos de $1 \mathrm{~m}$ entre linhas e 0,5 m entre plantas. A partir de abril de 2006, foram realizados cortes com intervalos médios de 60 e 90 dias na épocas das águas (5 cortes) e das secas (2 cortes), respectivamente, tendo sido realizados sete cortes. Em cada um deles foram anotados dados referentes à altura das plantas (ALP), produtividade de biomassa de forragem verde (PBV) em $\mathrm{t}$ ha ${ }^{-1} \mathrm{e}$ porcentagem de matéria seca (\%MS). Pela associação dessas últimas duas características foram obtidas as estimativas para a produtividade de biomassa de forragem seca (PBS).

Os dados de ALT, PBV e PBS de cada um dos cortes foram submetidos à análise de variância (análises individuais), considerando-se o modelo de blocos casualisados, com duas repetições. Também foi realizada análise conjunta, considerando-se todos os sete cortes empregando-se o esquema de parcela subdividida no tempo (RAMALHO et al., 2000). Posteriormente, utilizando as médias dos diferentes cortes, realizados nas épocas das águas ou das secas, foi realizada análise, em esquema fatorial (progênies $\mathrm{x}$ épocas), para a avaliação dos efeitos de estacionalidade de produção das progênies. Em todos os casos, as médias foram comparadas pelo teste de Scott e Knott (1974).

A avaliação da estabilidade do comportamento produtivo das progênies foi realizada por meio da metodologia proposta por Annicchiarico (1992). Nesse caso, os sete cortes de avaliação foram considerados como diferentes ambientes.

\section{RESULTADOS E DISCUSSÃO}

Os resultados das análises de variância detectaram diferenças significativas entre progênies e épocas do ano para todas as características consideradas, indicando que as progênies de $B$. ruziziensis apresentam potencial diferenciado para a utilização como forrageira e que o comportamento delas foi afetado pela época do ano. A interação entre progênies e épocas também foi significativa, indicando, de modo geral, que o desempenho produtivo das diferentes progênies não foi consistente na época das águas e da seca, ou seja, existe variabilidade no comportamento das progênies frente às variações ambientais avaliadas (seca x águas). Resultados semelhantes são relatados na literatura para diferentes espécies forrageiras, como alfafa (LÉDO et al., 2005), capim-elefante (SOUZA SOBRINHO et al., 2005) e Brachiaria (PEREIRA et al., 2005).

Tanto nas análises individuais, considerando-se cada corte realizado, como na conjunta (todos os cortes), para todas as características avaliadas, foram encontradas progênies de $B$. ruziziensis com médias semelhantes às melhores testemunhas avaliadas. Foi evidenciada a superioridade de muitas progênies não só em relação B. ruziziensis cv. Comum (disponível no mercado), mas também às principais cultivares utilizadas no Brasil $B$. brizantha $\mathrm{cv}$. Marandu e $B$. decumbens $\mathrm{cv}$. Basilisk, concordando com Souza Sobrinho et al. (2009). Ressaltase, portanto, a existência de variabilidade genética da espécie e o seu potencial produtivo, permitindo a exploração por meio do melhoramento genético.

As médias da ALT, PBV e PBS das progênies, para as épocas das águas e das secas estão apresentadas na Tabela 1. Para a altura de plantas, tanto nas águas como nas secas, e para as produtividades de biomassa de forragem verde e seca, na época das secas, as médias das progênies não foram separadas em diferentes grupos pelo teste utilizado, embora as análises estatísticas tenham indicado a presença de diferenças significativas e as amplitudes de variação para cada uma das características tenham sido amplas. Resultados semelhantes são encontrados na literatura (PEREIRA et al., 2005; SOUZA 
SOBRINHO et al., 2005) e refletem limitações dos testes de médias em geral, que são influenciados, entre outros fatores, pela diferença entre as médias e pelo número de tratamentos envolvidos (RAMALHO et al., 2000).

As médias da altura de plantas (ALT) e produtividade de biomassa de forragem verde e seca (PBV e PBS) alcançadas pelas progênies nas águas foram estatisticamente superiores àquelas observadas nos cortes realizados nos meses secos do ano (Tabela 1). Considerando-se as médias das progênies avaliadas, nas águas as produtividades de biomassa verde e seca foram 86,4 e 74,8\% superiores, respectivamente, àquelas observadas na seca. Esses resultados concordam com outros trabalhos realizados com leguminosas (LÉDO et al., 2005; MOREIRA et al., 1996) e gramíneas (BOTREL et al., 2002; SOARES FILHO et al., 2002; COSTA et al., 2005), confirmando o predomínio da produção da forragem, durante a época das águas. Botrel et al. (2002), avaliando 16 gramíneas forrageiras nas condições da Zona da Mata de Minas Gerais, incluindo a B. ruziziensis, observaram que apenas $26 \%$, em média, da produção de

Tabela 1 - Médias de altura de plantas ( $\mathrm{cm})$ e produtividades de biomassa verde (PBV) e seca (PBS) dos cinco piores e 15 melhores clones de Brachiaria ruziziensis, além das testemunhas (Brachiaria sp., B. decumbens, B. brizantha e B. ruziziensis), nas épocas das águas e das secas.

\begin{tabular}{|c|c|c|c|c|c|c|c|c|c|c|c|}
\hline \multicolumn{4}{|c|}{$\operatorname{ALT}(\mathrm{cm})$} & \multicolumn{4}{|c|}{$\operatorname{PBV}(\mathrm{t} / \mathrm{ha} /$ corte $)$} & \multicolumn{4}{|c|}{ PBS (t/ha/corte) } \\
\hline Prog & Águas & Prog & Secas & Prog & Águas* & Prog & Secas & Prog & Águas & Prog & Secas \\
\hline 312 & 73.0 & 300 & 54.5 & 319 & $9.4 b$ & 314 & 5.0 & 319 & $2.2 \mathrm{~b}$ & 300 & 1.2 \\
\hline 6 & 74.1 & 350 & 54.5 & 6 & $11.2 \mathrm{~b}$ & 300 & 5.1 & 6 & $2.6 \mathrm{~b}$ & 325 & 1.3 \\
\hline 310 & 74.6 & 88 & 56.3 & 333 & $12.9 \mathrm{~b}$ & 319 & 5.9 & 333 & $2.8 \mathrm{~b}$ & 314 & 1.3 \\
\hline 32 & 75.5 & 33 & 56.5 & 364 & $12.9 \mathrm{~b}$ & 23 & 5.9 & 14 & $2.9 \mathrm{~b}$ & 14 & 1.4 \\
\hline 4 & 76.1 & 15 & 57.0 & 310 & $13.0 \mathrm{~b}$ & 14 & 6.0 & 364 & $2.9 \mathrm{~b}$ & 23 & 1.4 \\
\hline 356 & 86.6 & 318 & 72.8 & 94 & $18.5 \mathrm{a}$ & 94 & 10.2 & 97 & $4.2 \mathrm{a}$ & 5 & 2.4 \\
\hline 315 & 87.1 & 349 & 73.3 & 342 & $18.5 \mathrm{a}$ & 338 & 10.3 & 359 & $4.2 \mathrm{a}$ & 352 & 2.4 \\
\hline 324 & 87.1 & 84 & 74.0 & 352 & $18.5 \mathrm{a}$ & 305 & 10.4 & 342 & $4.3 \mathrm{a}$ & 324 & 2.4 \\
\hline 349 & 87.1 & 338 & 74.0 & 360 & $18.6 \mathrm{a}$ & 329 & 10.4 & 34 & $4.3 \mathrm{a}$ & 353 & 2.5 \\
\hline 5 & 87.3 & 324 & 74.5 & 36 & $18.7 \mathrm{a}$ & 5 & 10.4 & 291 & $4.3 \mathrm{a}$ & 354 & 2.5 \\
\hline 8 & 87.3 & 353 & 74.5 & 5 & $19.0 \mathrm{a}$ & 10 & 10.5 & 83 & $4.4 \mathrm{a}$ & 342 & 2.5 \\
\hline 97 & 87.3 & 17 & 75.3 & 81 & $19.0 \mathrm{a}$ & 8 & 10.5 & 354 & $4.4 \mathrm{a}$ & 81 & 2.5 \\
\hline 339 & 87.3 & 85 & 76.3 & 356 & $19.3 \mathrm{a}$ & 354 & 10.5 & 10 & $4.4 \mathrm{a}$ & 82 & 2.6 \\
\hline 340 & 87.5 & 91 & 77.0 & 354 & $19.6 a$ & 342 & 10.5 & 326 & $4.5 \mathrm{a}$ & 17 & 2.6 \\
\hline 329 & 88.3 & 315 & 77.0 & 343 & $19.7 \mathrm{a}$ & 324 & 10.5 & 352 & $4.6 a$ & 36 & 2.6 \\
\hline 296 & 88.8 & 342 & 77.0 & 10 & $20.1 \mathrm{a}$ & 82 & 10.6 & 324 & $4.8 \mathrm{a}$ & 305 & 2.6 \\
\hline 85 & 89.6 & 334 & 77.8 & 324 & $20.3 \mathrm{a}$ & 336 & 10.8 & 343 & $4.8 \mathrm{a}$ & 8 & 2.6 \\
\hline 34 & 89.8 & 28 & 78.3 & 326 & $20.5 \mathrm{a}$ & 81 & 11.0 & 36 & $4.8 \mathrm{a}$ & 334 & 2.7 \\
\hline 36 & 90.3 & 8 & 79.0 & 336 & $22.5 a$ & 36 & 11.1 & 329 & $4.9 \mathrm{a}$ & 336 & 2.8 \\
\hline 336 & 90.3 & 360 & 89.5 & 329 & $23.3 \mathrm{a}$ & 360 & 14.5 & 336 & $5.2 \mathrm{a}$ & 360 & 4.2 \\
\hline B. sp. & 82.5 & B. sp. & 84.5 & B. sp. & $16.1 \mathrm{a}$ & B. sp. & 11.7 & B. sp. & $3.5 b$ & B. sp. & 3.2 \\
\hline Dec & 78.8 & Dec & 84.5 & Dec & $14.4 \mathrm{~b}$ & Dec & 13.7 & Dec & $3.3 b$ & Dec & 4.1 \\
\hline Briz & 63.6 & Briz & 62.5 & Briz & $14.0 \mathrm{~b}$ & Briz & 8.9 & Briz & $3.5 b$ & Briz & 2.4 \\
\hline Ruzi & 63.6 & Ruzi & 49.5 & Ruzi & $11.1 \mathrm{~b}$ & Ruzi & 5.1 & Ruzi & $2.5 b$ & Ruzi & 1.4 \\
\hline Médias & $82.1 \mathrm{~A}$ & & $66.9 \mathrm{~B}$ & & $15.8 \mathrm{~A}$ & & $8.5 \mathrm{~B}$ & & $3.6 \mathrm{~A}$ & & $2.1 \mathrm{~B}$ \\
\hline
\end{tabular}

*Letras minúsculas diferentes nas colunas, e maiúsculas na linha, indicam diferenças significativas entre as médias pelo teste de Scott-Knott, a 5\% de probabilidade de erro. 
forragem é gerada no período de inverno (seco). A maior produção de forragem na época das águas, comparativamente ao das secas, se deve aos fatores ambientais mais favoráveis, principalmente o fotoperíodo (MOREIRA et al., 1996), temperatura e umidade (SOARES FILHO et al., 2002). Considerando que a produção brasileira de leite e carne é baseada na utilização de pastagens (SOUZA SOBRINHO et al., 2009), a forte estacionalidade da produção, com redução da oferta de forragem na época seca tem consequências negativas sobre a produção animal (PEREIRA et al., 2005).

As médias de produção de biomassa verde obtidas na época das águas variaram de 23,3 a 9,4 t ha-1 e foram separadas em dois grupos distintos pelo teste de ScottKnott, com 53 progênies pertencendo ao grupo mais produtivo. Essas progênies apresentaram superioridade média de 23,2\% em relação ao grupo de materiais menos produtivo, ao qual foram incluídas todas as testemunhas avaliadas, à exceção da Brachiaria sp. (Tabela 1). Considerando-se a cultivar Comum (B. ruziziensis), a superioridade das melhores progênies foi de $58,8 \%$. Para as cultivares de $B$. decumbens (Basilisk) e B. brizantha (Marandu), que são os materiais mais amplamente difundidos nas pastagens brasileiras, observou-se produtividade de cerca de $3,5 \mathrm{t} / \mathrm{ha} /$ corte a mais de forragem por parte das 53 progênies mais produtivas.

Para a PBS, na época das águas, a amplitude de variação foi de 3,01 t de forragem seca/ha/corte, representando $82,9 \%$ da média geral. Assim como para a PBV, também se verificou a separação das médias em dois grupos distintos. Cinquenta e uma progênies foram classificadas no melhor grupo, superando em $27 \%$ a média de todas as cultivares utilizadas como testemunhas. Considerando-se apenas a cultivar Comum, as melhores progênies produziram, em média, aproximadamente 1,6 t de forragem seca/ha/corte, o que representa incremento de mais de $65 \%$ na produção do único material comercial de B. ruziziensis disponível no mercado (Tabela 1). Resultados semelhantes foram relatados por Souza Sobrinho et al. (2009), evidenciando a possibilidade de sucesso com a seleção dentro de $B$. ruziziensis. Reforça-se, assim, o potencial produtivo dos materiais avaliados, que superaram não só a cultivar existente de $B$. ruziziensis, mas também os melhores materiais comerciais de Brachiaria disponíveis no mercado.

Assim como comentado por Souza Sobrinho et al. (2005) para o capim-elefante, a B. ruziziensis também é uma forrageira perene, normalmente implantada para utilização durante alguns anos, e deve se apresentar produtiva por todo o cultivo. Por isso, embora tenha sido verificada interação significativa entre progênies e épocas de avaliação, o interessante para o produtor é que os genótipos tenham desempenho mais estável durante os diferentes cortes e épocas do ano. Assim, os resultados serão apresentados em função das médias obtidas nas análises conjuntas, envolvendo todos os cortes realizados nas diferentes épocas de avaliações.

Considerando-se as médias gerais, a amplitude de variação para a altura de plantas foi de $26,4 \mathrm{~cm}$ e as progênies foram separadas em dois grupos pelo teste de Scott-Knott. As cultivares Comum (B. ruziziensis) e Marandu (B. brizantha) foram classificadas no grupo de materiais com altura inferior, tendo apresentado os dois menores valores absolutos (Tabela 2). Para a PBV, a amplitude de variação entre as médias foi de $11,2 \mathrm{t}$ de forragem/ha/corte, correspondendo a $83,1 \%$ da média geral do experimento (Tabela 2). Houve a separação das médias em dois grupos pelo teste de Scott-Knott, com 62 progênies classificadas no melhor grupo, sempre com produções superiores à 13,7 t de forragem verde/ha/corte.

Para a produtividade de biomassa de forragem seca, na média de todos os cortes, houve separação das progênies em dois grupos pelo teste de Scott-Knott. Quarenta e seis progênies foram classificadas no grupo de maior produção, juntamente com as testemunhas B. decumbens e Brachiaria sp. A média das progênies foi $13 \%$ superior a das testemunhas, enquanto as 10 progênies mais produtivas, em valores absolutos, mostraram-se $32 \%$ superiores à melhor testemunha (Brachiaria sp.). Considerando-se a cultivar Comum, as 46 progênies do grupamento superior produziram, em média, mais 1,4 t de forragem seca/ha/corte. A progênie 336 produziu mais que o dobro de forragem seca que essa cultivar, reforçando a variabilidade genética existente dentro da espécie e o potencial produtivo passível de ser explorado pelo melhoramento genético.

A análise de estabilidade e adaptabilidade foi utilizada buscando-se identificar materiais com desempenho produtivo mais estável nos diferentes cortes e épocas de avaliação. O método de Annichiarico (1992) permite estimar o risco de adoção de determinado material em relação à média dos demais. Os resultados desta análise (Tabela 3) reforçam a existência de interação genótipos e épocas (cortes), mencionada anteriormente. A estimativa do índice de confiança de Annicchiarico foi inferior a 100\% para muitas progênies, tanto para a altura de plantas como para as produtividades de biomassa verde e seca de forragem. Isso indica que o risco de adoção dessas progênies é grande, ou seja, na melhor das hipóteses algumas delas apresentaram produção semelhante à média nos diferentes cortes realizados. 
Tabela 2 - Médias gerais (todos os cortes) de altura de plantas (ALT) e produtividades de biomassa verde (PBV) e seca (PBS) dos cinco piores e 15 melhores progênies de meio-irmãos de Brachiaria ruziziensis, além das testemunhas (Brachiaria sp., B. decumbens, B. brizantha e B. ruziziensis).

\begin{tabular}{|c|c|c|c|c|c|}
\hline Progênies & $\operatorname{ALT}(\mathrm{cm})^{*}$ & Progênies & PBV (t/ha/corte) & Progênies & $\operatorname{PBS}(\mathrm{t} / \mathrm{ha} /$ corte $)$ \\
\hline 312 & $68.8 \mathrm{~b}$ & 319 & $8.4 \mathrm{~b}$ & 319 & $2.0 \mathrm{~b}$ \\
\hline 6 & $69.4 \mathrm{~b}$ & 6 & $9.9 \mathrm{~b}$ & 6 & $2.3 b$ \\
\hline 310 & $69.8 \mathrm{~b}$ & 314 & $11.1 \mathrm{~b}$ & 14 & $2.5 \mathrm{~b}$ \\
\hline 32 & $70.6 \mathrm{~b}$ & 332 & $11.3 b$ & 325 & $2.6 \mathrm{~b}$ \\
\hline 88 & $70.9 \mathrm{~b}$ & 14 & $11.3 \mathrm{~b}$ & 312 & $2.6 \mathrm{~b}$ \\
\hline 17 & $82.2 \mathrm{a}$ & 291 & $15.3 \mathrm{a}$ & 85 & $3.6 \mathrm{a}$ \\
\hline 318 & $82.2 \mathrm{a}$ & 298 & $15.3 \mathrm{a}$ & 5 & $3.6 \mathrm{a}$ \\
\hline 338 & $82.4 \mathrm{a}$ & 338 & $15.3 \mathrm{a}$ & 97 & $3.6 \mathrm{a}$ \\
\hline 81 & $82.5 \mathrm{a}$ & 83 & $15.5 \mathrm{a}$ & 359 & $3.6 \mathrm{a}$ \\
\hline 97 & $82.6 \mathrm{a}$ & 353 & $15.7 \mathrm{a}$ & 94 & $3.7 \mathrm{a}$ \\
\hline 353 & $82.7 \mathrm{a}$ & 352 & $16.0 \mathrm{a}$ & 34 & $3.7 \mathrm{a}$ \\
\hline 28 & $83.1 \mathrm{a}$ & 94 & $16.1 \mathrm{a}$ & 81 & $3.7 \mathrm{a}$ \\
\hline 349 & $83.1 \mathrm{a}$ & 342 & $16.2 \mathrm{a}$ & 83 & $3.7 \mathrm{a}$ \\
\hline 296 & $83.3 \mathrm{a}$ & 343 & $16.5 \mathrm{a}$ & 342 & $3.8 \mathrm{a}$ \\
\hline 329 & $83.3 \mathrm{a}$ & 36 & $16.5 \mathrm{a}$ & 291 & $3.8 \mathrm{a}$ \\
\hline 324 & 83.5 & 5 & $16.6 \mathrm{a}$ & 10 & $3.8 \mathrm{a}$ \\
\hline 91 & $83.6 \mathrm{a}$ & 356 & $16.7 \mathrm{a}$ & 326 & $3.8 \mathrm{a}$ \\
\hline 34 & $83.9 \mathrm{a}$ & 81 & $16.8 \mathrm{a}$ & 354 & $3.8 \mathrm{a}$ \\
\hline 342 & $83.9 \mathrm{a}$ & 354 & $17.0 \mathrm{a}$ & 352 & $4.0 \mathrm{a}$ \\
\hline 315 & $84.2 \mathrm{a}$ & 10 & $17.3 \mathrm{a}$ & 343 & $4.0 \mathrm{a}$ \\
\hline 36 & $84.4 \mathrm{a}$ & 326 & $17.4 \mathrm{a}$ & 324 & $4.1 \mathrm{a}$ \\
\hline 8 & $84.9 \mathrm{a}$ & 360 & $17.4 \mathrm{a}$ & 360 & $4.1 \mathrm{a}$ \\
\hline 336 & $84.9 \mathrm{a}$ & 324 & $17.5 \mathrm{a}$ & 329 & $4.2 \mathrm{a}$ \\
\hline 85 & $85.8 \mathrm{a}$ & 336 & $19.1 \mathrm{a}$ & 36 & $4.2 \mathrm{a}$ \\
\hline 360 & $86.0 \mathrm{a}$ & 329 & $19.6 \mathrm{a}$ & 336 & $4.5 \mathrm{a}$ \\
\hline B. sp. & $83,1 \mathrm{a}$ & B. sp. & $14,8 \mathrm{a}$ & $B$. sp. & $3,4 \mathrm{a}$ \\
\hline B. decumbens & $80.4 \mathrm{a}$ & B. decumbens & $14.2 \mathrm{a}$ & B. decumbens & $3.6 \mathrm{a}$ \\
\hline B. brizantha & $63.3 b$ & B. brizantha & $12.5 \mathrm{~b}$ & B. brizantha & $3.2 \mathrm{~b}$ \\
\hline B. ruziziensis & $59.6 \mathrm{~b}$ & B. ruziziensis & $9.4 \mathrm{~b}$ & B. ruziziensis & $2.2 \mathrm{~b}$ \\
\hline Média & 77,8 & & 13,7 & & 3,2 \\
\hline
\end{tabular}

*Letras diferentes nas colunas indicam diferenças significativas entre as médias pelo teste de Scott-Knott, a 5\% de probabilidade de erro.

Por outro lado, as progênies 336, 360, 36, 329, 324, 352, 354 e 343 foram as que apresentaram os maiores índices de confiabilidade de Annicchiarico (Wi) para PBS, sempre superiores à $120 \%$. Esse resultado indica que tais progênies, na média dos cortes, deverão apresentar, na pior das hipóteses, produtividades de forragem $20 \%$ superiores à média. Ou seja, há menor risco de adoção desses materiais (OLIVEIRA et al., 2007). Essas progênies apresentaram, ainda, índices de confiança superiores à $100 \%$ para altura de plantas e PBV, à exceção da progênie 352 , cujo índice foi de $96,2 \%$ para a altura de plantas (Tabela 3). 
Tabela 3 - Médias de altura de plantas (ALT) e produtividades de matéria verde (PBV) e seca (PBS) de forragem de progênies de Brachiaria ruziziensis (5 piores e 15 melhores) e das testemunhas, e respectivos índices de confiança de Annicchiarico (Wi).

\begin{tabular}{|c|c|c|c|c|c|c|}
\hline Progênie & $\operatorname{ALT}(\mathrm{cm})$ & $\mathrm{Wi}(\%)$ & $\operatorname{PBV}\left(\mathrm{t} \mathrm{ha}^{-1}\right.$ corte $\left.^{-1}\right)$ & $\mathrm{Wi}(\%)$ & PBS $\left(\mathrm{t} \mathrm{ha}^{-1}\right.$ corte $\left.^{-1}\right)$ & $\mathrm{Wi}(\%)$ \\
\hline 319 & 72.8 & 93.4 & 8.4 & 62.6 & 2.0 & 64.6 \\
\hline 6 & 69.4 & 89.3 & 9.9 & 72.2 & 2.3 & 73.1 \\
\hline 14 & 76.1 & 97.7 & 11.3 & 80.2 & 2.5 & 76.4 \\
\hline 325 & 76.6 & 97.9 & 11.9 & 85.0 & 2.6 & 79.1 \\
\hline 312 & 68.8 & 88.6 & 11.9 & 87.8 & 2.6 & 81.6 \\
\hline 291 & 78.6 & 101.4 & 15.3 & 111.2 & 3.8 & 115.8 \\
\hline 81 & 82.5 & 105.9 & 16.8 & 122.9 & 3.7 & 116.1 \\
\hline 5 & 81.7 & 104.8 & 16.6 & 121.9 & 3.6 & 116.1 \\
\hline 326 & 78.1 & 99.8 & 17.4 & 124.3 & 3.8 & 116.5 \\
\hline 83 & 80.4 & 104.0 & 15.5 & 112.1 & 3.7 & 116.7 \\
\hline 342 & 83.9 & 108.3 & 16.2 & 119.2 & 3.8 & 118.6 \\
\hline 10 & 81.1 & 104.6 & 17.3 & 128.7 & 3.8 & 119.3 \\
\hline 343 & 79.1 & 102.2 & 16.5 & 118.5 & 4.0 & 120.9 \\
\hline 354 & 81.4 & 104.1 & 17.0 & 123.8 & 3.8 & 120.9 \\
\hline 352 & 74.6 & 96.2 & 16.0 & 117.6 & 4.0 & 123.8 \\
\hline 324 & 83.5 & 107.8 & 17.5 & 126.8 & 4.1 & 127.3 \\
\hline 329 & 83.3 & 107.3 & 19.6 & 140.6 & 4.2 & 128.8 \\
\hline 36 & 84.4 & 108.5 & 16.5 & 122.7 & 4.2 & 129.5 \\
\hline 360 & 86.0 & 112.5 & 17.4 & 131.2 & 4.1 & 137.9 \\
\hline 336 & 84.9 & 109.4 & 19.1 & 138.5 & 4.5 & 139.5 \\
\hline B. sp. & 83.1 & 107.9 & 14.8 & 111.2 & 3.4 & 113.7 \\
\hline B. decumbens & 80.4 & 105.1 & 14.2 & 109.2 & 3.6 & 121.3 \\
\hline B. brizantha & 63.3 & 82.9 & 12.5 & 91.9 & 3.2 & 100.4 \\
\hline B. ruziziensis & 59.6 & 76.3 & 9.4 & 67.0 & 2.2 & 68.3 \\
\hline
\end{tabular}

Comparando-se com as testemunhas, observa-se que os índices de confiança de Annicchiarico estimados para algumas progênies $(352,324,329,36,360$ e 336) foram superiores às melhores testemunhas avaliadas, reforçando o potencial produtivo e a confiabilidade dos materiais experimentais. Para a PBS, por exemplo, o índice obtido por algumas progênies foi mais de duas vezes àquele da cultivar Comum (B. ruziziensis).

Os resultados obtidos nesse trabalho evidenciam variabilidade genética para as características relacionadas à produtividade de forragem (SOUZA SOBRINHO et al., 2009) e reforçam a possibilidade de sucesso com a seleção dentro de B. ruziziensis. Esperase, assim, que a continuidade do programa de melhoramento genético dessa espécie possa resultar na obtenção de novas cultivares que venham contribuir efetivamente para o incremento nas produtividades de carne e leite do Brasil.

\section{CONCLUSÕES}

Existe variabilidade genética entre progênies de B. ruziziensis para a altura de plantas e produtividades de biomassa de forragem verde e seca, tanto na época das águas como na seca.

Apesar da maior produção de forragem das progênies de $B$. ruziziensis na época das águas, é possível identificar e selecionar materiais com médias mais elevadas e com produção mais estável ao longo do ano. 


\section{REFERÊNCIAS BIBLIOGRÁFICAS}

ANNICCHIARICO, P. Cultivar adaptation and recomendation from alfafa trial in Northern Italy. Journal of Genetics and Breeding, Rome, v.46, p.269278, 1992.

BOTREL, M.A. et al. Potencial forrageiro de gramíneas em condições de baixas temperaturas e altitude elevada. Pesquisa Agropecuária Brasileira, Brasília, v.37, n.3, p.393-398, 2002.

COSTA, K.A.P. et al. Efeito da estacionalidade na produção de matéria seca e composição bromatológica da Brachiaria brizantha cv. Marandu. Ciência Animal Brasileira, Goiânia, v.6, n.3, p.187-193, jul./set. 2005.

FERNANDES, L.de O.; REIS, R.A.; PAES, J.M.V. Efeito da suplementação no desempenho de bovinos de corte em pastagem de Brachiaria brizanhta cv. Marandu. Ciência e Agrotecnologia, v. 34, n. 1, p. 240-248, jan./fev., 2010.

LÉDO, F.J.S. et al. Adaptabilidade e estabilidade de cultivares de alfafa avaliadas em Minas Gerais. Ciência e Agrotecnologia, v. 29, n. 2, p. 409-414, mar./abr., 2005.

MOREIRA, A.; EVANGELISTA, A.R.; RODRIGUES, G.H.S. Avaliação de cultivares de alfafa na região de Lavras, Minas Gerais. Pesquisa Agropecuária Brasileira, Brasília, v.31, n.6, p.407-411, jun. 1996.

OLIVEIRA, J.S. et al. Adaptabilidade e estabilidade de cultivares de milho destinados à silagem em bacias leiteiras do estado de Goiás. Pesquisa Agropecuária Tropical, Goiânia, v.37, n.1, p.45-50, 2007.

OLIVEIRA, J.S.e et al. Valor nutricional da planta, padrões de fermentação e qualidade da silagem de triticale em seis idades de corte. Ciência e

Agrotecnologia, v. 34, n. 3, p. 765-772, maio/jun., 2010.

PEREIRA, A.V. et al. Selection of interspecific Brachiaria hybrids to intensify milk production on pastures. Crop Breeding and Applied Biotechnology, Viçosa, v.5, n.1, p.99-104, 2005.

PEREIRA, A.V. et al. Melhoramento de forrageiras tropicais. In: NASS, L.L. et al. Recursos genéticos e melhoramento de plantas. Rondonópolis: Fundação MT, 2001.

RAMALHO, M.A.P.; FERREIRA, D.F.; OLIVEIRA, A.C. de. Experimentação em genética e melhoramento de plantas. Lavras: UFLA, 2000. 326p.

SCOTT, A.J.; KNOTT, M. A cluster analysis method for grouping means in the analyses of variance. Biometrics, Arlington, v.30, p.507-512, 1974.

SOARES FILHO, C.V.; RODRIGUES, L.R.; PERRI, S.H.V. Produção e valor nutritivo de dez gramíneas forrageiras na região Noroeste do Estado de São Paulo. Acta Scientiarum, Maringá, v.24, n.5, p.1377-1384, 2002.

SOUZA SOBRINHO, F. Melhoramento de forrageiras no Brasil. In: EVANGELISTA, A.R. et al. Forragicultura e pastagens: temas em evidência. Lavras: UFLA, 2005. p.65-120.

SOUZA SOBRINHO, F. et al. Avaliação agronômica de híbridos interespecíficos entre capim-elefante e milheto. Pesquisa Agropecuária Brasileira, Brasília, v.40, n.9, p.873-880, set. 2005.

Melhoramento de gramíneas forrageiras na Embrapa Gado de Leite. In: EVANGELISTA, A.R.; SOUZA, F.F. (Eds.). Forragicultura e pastagem. Lavras: UFLA, 2009. p.98-111. 